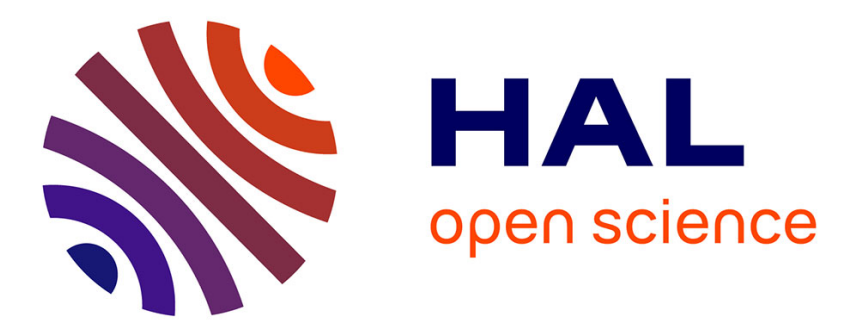

\title{
Gesture Helps Second and Foreign Language Learning and Teaching
}

\author{
Gale Stam, Marion Tellier
}

\section{To cite this version:}

Gale Stam, Marion Tellier. Gesture Helps Second and Foreign Language Learning and Teaching. Aliyah Morgenstern \& Susan Goldin-Meadow. Gesture in Language: Development Across the Lifespan, Mouton de Gruyter; APA, 2021, 978-1-4338-3629-9. 10.1037/0000269-014 . hal-03464264

\section{HAL Id: hal-03464264 \\ https://hal.science/hal-03464264}

Submitted on 3 Dec 2021

HAL is a multi-disciplinary open access archive for the deposit and dissemination of scientific research documents, whether they are published or not. The documents may come from teaching and research institutions in France or abroad, or from public or private research centers.
L'archive ouverte pluridisciplinaire HAL, est destinée au dépôt et à la diffusion de documents scientifiques de niveau recherche, publiés ou non, émanant des établissements d'enseignement et de recherche français ou étrangers, des laboratoires publics ou privés. 
This is the authors' manuscript of the following chapter

Please note that some minor changes (in the wording) have occurred in the final version.

This is chapter 14 in the edited volume.

STAM, G. \& TELLIER, M. (2021). Gesture Helps Second and Foreign Language Learning and Teaching. In Morgenstern A. \& Goldin-Meadow S. (Eds). Gesture in Language: Development Across the Lifespan (pp.336-363). Mouton de Gruyter - APA.

\title{
14. Gesture Helps Second and Foreign Language Learning and Teaching
}

\author{
Gale Stam, National Louis University \\ Marion Tellier, Aix Marseille Univ., CNRS, LPL
}

From the perspective that language and language usage consist of both speech and gesture (McNeill 1992, 2005, 2012) a number of studies have been conducted to examine gesture's role in second language (L2) acquisition over the past thirty years. These studies have demonstrated the important role that gesture plays in both second and foreign language learning and teaching ${ }^{1}$ (for reviews, see Gullberg and McCafferty 2008; Stam 2013; Stam and McCafferty 2008; Stam and Buescher 2018; Tellier 2014).

However, despite the growing interest in gesture and L2 learning and teaching among a number of researchers, the topic of gesture and its importance in understanding L2 acquisition is still not considered in most mainstream second language acquisition (SLA) studies. These studies on L2 learning and teaching have mainly focused on the analysis of speech production and seen gestures as peripheral to the process of learning and teaching. However, gestures play a very strong role in both learning and teaching because verbal language is only half of the picture (it provides a window only onto verbal thought and not imagistic thought), it is not always the most efficient medium for communication especially when there is an asymmetry in language proficiency between a learner and a teacher or a native speaker. L2 learning and teaching are interconnected and can be considered as two sides of the same coin: for instance, on the one hand, learners use gestures to scaffold their speech elaboration, and on the other hand, teachers use gestures to scaffold their speech comprehension by the learners. In addition, learners' gestures indicate their language

\footnotetext{
${ }^{1}$ Second language learning and teaching refers to learning and teaching a language in a country where the language is spoken on a daily basis, whether it is the learner's second, third, or fourth language. Foreign language learning and teaching refers to learning and teaching another language in a person's home country, where it is not the language for communication. In this chapter, we will use L2 to refer to both.
} 
proficiency and comprehension of material, important aspects for teachers to take into consideration in their teaching.

This chapter, although it focuses on adult learners, will provide evidence for why it is important to consider gestures in both L2 learning and teaching for all age ranges. It begins by defining co-speech gestures and pedagogical gestures. Next, it discusses how learners' cospeech gestures show whether they are conceptualizing in their L1, their L2, or a combination of the two and to what extent different tasks affect the types of gestures learners produce. Then, it shifts to pedagogical gestures and illustrates how teachers engage their bodies in different ways in the classroom, the various functions of the gestures teachers use, and in what manner teachers vary their speech and gesture when engaging with non-native speakers, and what this tells us about teaching and communication.

\subsection{Speech and Gesture}

When we communicate, we do not just move our mouths to make the sounds of a language, we also move our hands, our heads, and our bodies. These movements of the hands that accompany speech are referred to as co-speech gestures (Kendon 2004; McNeill 1992, 2005), and together with speech they form a unit that expresses both the verbal and imagistic thought of a speaker (McNeill 1992). Co-speech gestures, which are often produced without conscious awareness, are synchronous with speech, cannot be understood independently of speech, perform similar pragmatic functions as speech, and are multifunctional in that they perform both cognitive and communicative functions often at the same time (Stam and McCafferty 2008; Stam 2018a; Stam and Tellier 2017). These gestures are often classified on the basis of their semiotic properties (McNeill 2012; Stam 2013) that is what they represent such as iconicity, metaphoricity, deixis, temporal highlighting, or social interactivity or on the basis of their pragmatic function, that is what their discourse function is such as representational, discursive, deictic, interactive, and word searching (Kendon 2004; Stam 2018b).

Besides co-speech gestures, there are a few other types of gestures and bodily movements that are relevant for $\mathrm{L} 2$ learning and teaching. These include speech-linked gestures, emblems, mimes, and pedagogical gestures. All of these are performed with some degree of conscious awareness (Stam and Tellier 2017; Stam 2018a). Speech-linked gestures are similar to co-speech gestures in that they also occur with speech, but they differ in terms of their synchrony (Stam 2013). Speech-linked gestures are asynchronous with speech and occur during a pause in speech thus filling a speech gap such as in the following utterance "Sylvester went [gesture of an object flying out laterally]" (McNeill 2005: 5). These gestures are used by learners when they lack vocabulary or by teachers as a teaching strategy, leaving a blank and performing a gesture so that learners can supply the missing word or words (Stam 
2018a).

Emblems are codified, culturally specific gestures such as the "thumbs down" gesture (fist with thumb down) that are known and learned by all members of a languacultural (Agar 1994) group (Stam 2013, 2018a). These gestures are performed with some degree of conscious awareness and occur both with and without speech. The form of an emblem is fixed, but its meaning can vary from culture to culture. Thus, emblems need special attention in the L2 classroom. They need to be taught (e.g., von Raffler-Engel 1980; Wylie, 1985) so that L2 learners become competent in their usage (Stam 2018a). It is also important for L2 teachers to be aware of their own usage of these gestures because they can be misunderstood if they are used without any explanation (see Hauge 1998, 1999; Tellier and Cadet 2013).

Mimes (or pantomimes) are gestures and body movements that are performed without speech and with conscious awareness (Stam 2013). They depict actions, objects, or entire stories and are used by learners when they lack vocabulary or by teachers when they are attempting to get learners to guess.

Pedagogical gestures (Tellier, 2008a) are gestures that are used in the classroom. These gestures are often made with conscious awareness, and they perform several different functions. These include cospeech gestures (mainly deictics - pointing gestures and iconics gestures that represent concrete actions and objects), speech-linked gestures, mimes and emblems. Pedagogical gestures will be discussed further in the section on gestures and L2 teaching.

One interesting aspect about gestures and $L 2$ learning and teaching is that the balance between gesture and speech may vary from that of the speech and gesture of a native speaker. Learners may use gestures to cope with weak language proficiency or gesture frequency and timing may differ as learners work out their utterances in the L2 (Stam 2006b). Similarly, when addressing a language learner, teachers (even preservice teachers) may use gestures in a way that helps the learner access meaning (Tellier and Stam, 2012; Tellier, Stam, and Bigi 2013; Stam and Tellier, 2017; Tellier, Stam \& Ghio, 2021). Thus, studying gestures in L2 learning and teaching sheds a new light on our comprehension of gestures and how they combine with speech and thought. Let us now turn to gesture and L2 learning.

\subsection{Gesture And Second Language Learning}

Empirical research on gesture and SLA over the past thirty years has examined gestures and L2 learning from a number of perspectives (for reviews, see Gullberg 2010; Gullberg and McCafferty 2008; Gullberg, de Bot, and Volterra 2008; Stam 2013; Stam and Buescher 2018; Stam and McCafferty, 2008). Among these are learners' rate of gesturing in their L2, the types and functions of the gestures learners produce, the impact of learners' gestures in assessing their oral proficiency, the role of learners' gestures in lexical retrieval, 
what learners' gestures reveal about their thinking in their L2, particularly their thinking for speaking, and the role of gestures in enhancing L2 learning. In the next sections, we will address the topics of oral proficiency assessment, lexical retrieval, learners' conceptualizations in their L2, task effects on gestures, and how gestures can enhance L2 learning.

\subsubsection{Second Language Learners' Gestures Impact On Oral Proficiency Ratings}

Several researchers (Gullberg 1998; Jenkins and Parra 2003; Nambiar and Goon 1993; Neu 1990; Stam 2006a) have shown that learners' gestures have an effect on how their oral proficiency is rated. For example, Gullberg (1998) found that learners' oral proficiency was rated significantly higher in a video-condition, where the raters saw the learners' gestures, than in an audio only condition, where raters could only hear the learners' speech. Furthermore, in their comparison of ratings of oral proficiency interviews in a face-to-face and an audio-only condition, Nambiar and Goon (1993) found that learners' oral proficiency was rated significantly higher in the face-to-face condition. In both of these studies, hearing not only the speech of the learners' but also seeing their mouth movements and gestures benefitted the raters (Drijvers and Özyürek 2016). However, it is not just seeing learners' gestures that makes a difference in how their oral proficiency is rated. An important factor is the degree to which their gestures are close to those of the target language and culture. Neu (1990), Jenkins and Parra (2003), and Stam (2006a) all found that learners' oral proficiency was rated higher when their gestures were closer to the target language and culture than when they were not. When they were not, their oral proficiency was rated lower even if their speech was more fluent. Thus, as these studies indicate how learners gesture has an impact on how their oral proficiency is rated whether the raters are aware that they are paying attention to the learners' gestures or not.

\subsubsection{Second Language Learners' Gestures And Lexical Retrieval}

According to the lexical retrieval hypothesis, iconic gestures (gestures that represent concrete actions and objects) are produced when speakers have difficulty finding words, and these gestures facilitate word finding (for a review, see Stam 2012). However, Beattie and Coughlan $(1998,1999)$ have shown that lexical retrieval problems alone do not account for iconic gestures and that sometimes the gestures during lexical retrieval are iconic and sometimes they are not. This raises the question of what kinds of gestures $L 2$ learners produce when they are having trouble finding a word. This is an interesting question because L2 learners may have gaps in their vocabulary based on their exposure to the L2 and proficiency level and may lack the vocabulary for different domains and tasks.

Only a few studies have examined this topic. For instance, Gullberg (1998) found that L2 learners sometimes used gestures as a communication strategy to deal with fluency, grammar, lexical retrieval problems and these included metaphoric (gestures that represent 
abstract concepts) as well as iconic gestures. Additionally, Stam $(2001,2012)$ investigated the types of gestures L2 learners produced during lexical searches (the word search phase), lexical retrievals (the word finding phase), and lexical failures (the inability to find a word). She found that the types of gestures learners produced depended on whether they knew the word and were trying to retrieve it or were asking the interlocutor for help. Searches that occurred with lexical retrieval often had iconic gestures with superimposed beats (small rhythmic movements of the hands or fingers produced on another gesture) with a larger beat occurring with the retrieved word, but these were not the only type of gesture that occurred during searches. There were also aborted (gestures that are started but not completed), word search, and deictic (pointing) gestures to name a few. Gestures that occurred with failures were primarily iconic and aborted gestures that indicated what learners were thinking but did not express verbally. L2 gesture and lexical retrieval is an area that could use further study.

\subsubsection{What Second Language Learners' Gestures Reveal About Their Thinking In Their L2}

L2 learners' gestures provide SLA researchers with a more complete picture of how they are thinking when they are speaking in their $\mathrm{L} 2$ than looking at speech alone does (Stam 2006b, 2008, 2016, 2018b). For example, Stam (2008) demonstrated that if we looked at only the speech of an L2 learner engaged in a cartoon narration task (Example 1), we see that the learner could produce the utterance "the Tweety has a / bowling ball /" and that she was having difficulty describing what she had seen before this. We do not know what she was thinking about.

\begin{tabular}{|c|c|c|}
\hline (1) & $\begin{array}{l}\text { and }<\text { uhm }>\text { the Tweety / / }<\text { uhm }>/ 2 \\
<m m m>/ / /<\mathrm{mhff}>\# \\
\text { the Tweety has a / bowlina ball / }\end{array}$ & (Stam 2008: 252) \\
\hline
\end{tabular}

In contrast, when the learner's gestures are also looked at (Example 2), it becomes clear that the learner was trying to describe part of the cartoon she had just watched, where Tweety (one of the main characters) threw a bowling ball down a drainpipe. We can also see that even though she could produce the utterance "The Tweety has a / bowling ball /, her gestures reveal that her thinking is very segmented as she had a gesture for the subject and verb (the Tweety has), another one for the article (a), and a third gesture for the direct object (bowling ball).
$(2)$
and $<$ uhm $>$ t $[\text { he Tweety / / <uhm }>]^{3}$

\footnotetext{
2 Transcription for Examples 1 to 10 use the following convention from McNeill (1992) <> = filled pauses and elongation, $/$ = unfilled pauses, \# = breath pauses, and ${ }^{*}=$ repetitions or self-corrections . ${ }^{3}$ All examples are coded according to McNeill's (1992) coding scheme, in which the gesture phrase (the movement of the hand from start to finish) is enclosed in square brackets, the stroke (the part of the gesture with meaning) is indicated in bold, any holds - prestroke or poststroke (the maintaining of
} 


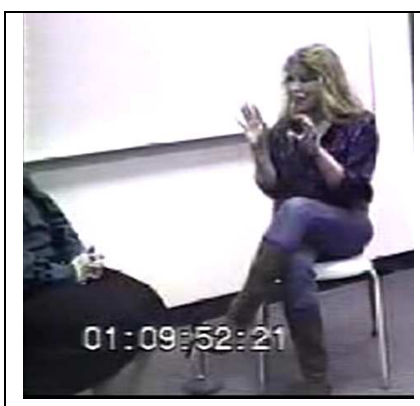

iconic: both hands at upper right and left, move away from body and down and repeat movement $<$ Tweety throwing the bowling ball>

[/ $<\mathrm{mmm}>$ ]

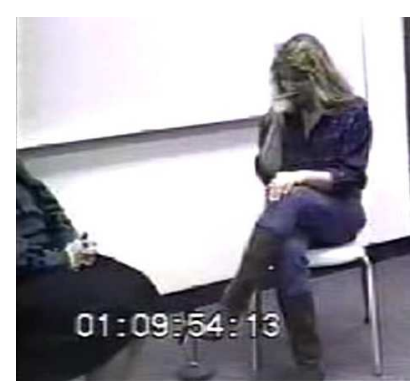

word search ${ }^{4}$ : left hand rises to nose, index finger touches nose, and retracts <trying to find the words>

$[/ / /]<\operatorname{mhff}>\#$

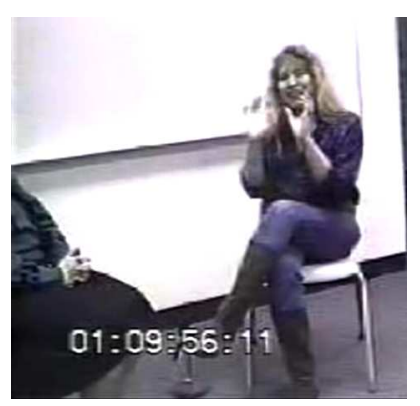

iconic (repetition to reduced repetition of previous iconic): both hands at upper right and left, move away from body and down and repeat as a smaller movement $<$ Tweety throwing the bowling ball>

[ [the Tweety has] [a /] [bo<0>wling ball / ] ]

a

b

C

a hand shape in a particular position) is indicated by underlined, and any gesture units (two or more gesture phrases that are related) are enclosed in another set of square brackets.

${ }_{4}^{4}$ This is updated from Stam (2008: 252). 

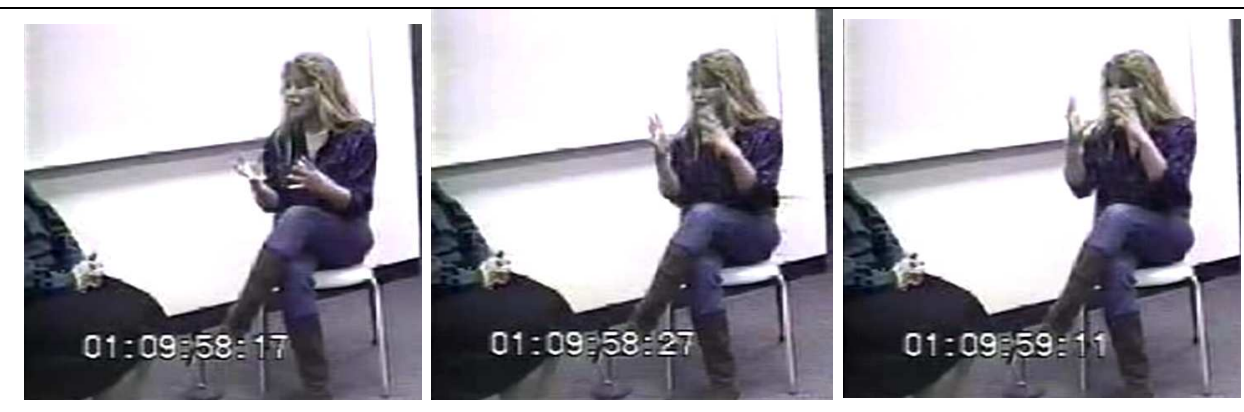

a: iconic: both hands move to their respective sides and up to upper chest< Tweety holding bowling ball + shape of bowling ball>

b: aborted iconic: both hands continue from previous movement, move up to neck, out to respective sides, and back to neck<bowling ball>

c: iconic: both hands continue from previous movement, move up slightly open to their respective sides, then down to lower chest, and hold<showing shape of bowling ball>

The majority of studies that have examined L2 learners' gestures and what they tell us about learners' conceptualizations have focused on the domain of motion events. These studies (e.g., Aguiló \& Negueruela-Azarola 2015; Brown 2008, 2015; Brown \& Gullberg 2008, 2011; Choi \& Lantolf 2008; Kellerman \& van Hoof 2003; Negueruela et al 2004; Stam 2006b, $2008,2010,2014,2015,2017)$ have been done within the framework of Talmy's (2000) and Slobin's (2006) classification of languages into verb-framed (with path encoded on the verb), satellite-framed (with path encoded on a satellite, an adverb or preposition), and equipollentlyframed (with both path and manner encoded on verbs) languages. They are also based on Slobin's (1991) thinking for speaking hypothesis, which proposes that "in acquiring a native language, a child learns a particular way of thinking for speaking." (Slobin 1991: 12) In other words, in L1 acquisition, children learn the grammatical constructions and lexicon of the L1 that both provide them with a framework for the expression of thoughts, events, and feelings and guide their verbal expression as they engage in speaking (Stam 2010). The typological differences that exist between languages are important in L2 acquisition especially if different patterns of thinking for speaking exist between a learners' L1 and L2 because in order to become proficient in their $L 2$, learners must learn another pattern of thinking for speaking (Stam 1998; Cadierno and Lund 2004). One way to have a more complete view of whether learners are thinking for speaking in their L2 is to examine not only their speech but also the timing of their gestures (Stam 2006a, 2006b, 2008).

Studies that have looked at learners' thinking for speaking have investigated how the motion events components of path, manner, and ground are expressed linguistically and gesturally in different languages and how L2 speakers express them in their L2. These studies 
have looked at what gestures are produced and what speech elements they accompany. They found that the L2 learners were able to produce grammatically correct sentences in their L2, but that their gestures showed that the learners were not thinking for speaking in their L2: their thinking for speaking was somewhere between their L1 and their L2. In other words, the learners' gestures indicated their interlanguage systems (Stam 2008, 2010). This would not have been discernible by looking at speech alone.

Examples 3-5 from a longitudinal study of changes in a L2 learner's (Rosa's) thinking for speaking (Stam 2017: 354) illustrate how speech alone is misleading. In describing a scene from a cartoon she saw where Sylvester (the cat) goes up the drainpipe, Rosa produces grammatically correct utterances starting in 1997 and continuing in 2006 and 2011, and they are not much different from that of a Native English speaker (Example 6). All the utterances are complete sentences with subject verb agreement and the inclusion of a satellite for path.

\begin{tabular}{|ll|}
\hline (3) $\quad \begin{array}{l}\text { Rosa-Speech } 1997 \\
\text { he* the cat went through the* / / the }<\text { e }>\text { pipe / and * but the* }\end{array}$ \\
(4) \\
Rosa-Speech 2006 \\
he goes inside the pipe the* / \\
(5) Rosa-Speech 2011 \\
so h<e $>$ // \#breath goes through one of the pipes \\
(6) $\quad \begin{array}{l}\text { Native English speaker-Speech } \\
\text { a }<\text { a }>\text { nd / / he goes }<\text { S }>\text { up / through the pipe this time \# }\end{array}$
\end{tabular}

From this data, we could conclude that Rosa, whose first language is Spanish, is thinking for speaking in her L2 English. However, when we look at her speech and gesture in Examples 7-9 compared with that of the Native English speaker in Example 10, we see that is not the case, and we also see how Rosa's thinking for speaking in English has changed from 1997 to 2011.

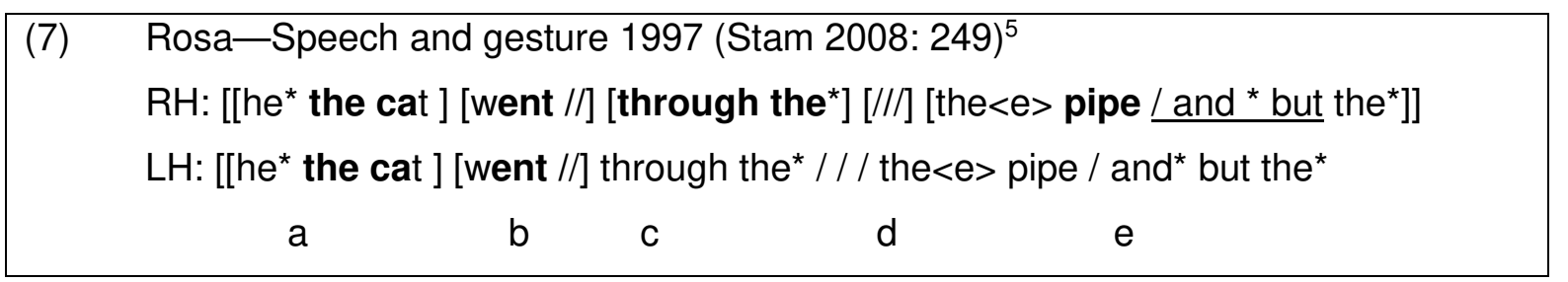

\footnotetext{
${ }^{5}$ Photos in Examples 7-9 are published by permission of John Benjamins Publishing Company. They were originally published in Stam, Gale. 2017. Verb framed, satellite framed or in between? A L2 learner's thinking for speaking in her L1 and L2 over 14 years. In Iraide Ibarretxe-Antuñano (ed.), Motion and space across languages: theory and applications, 329-365. Philadelphia/ Amsterdam: John Benjamins. https://benjamins.com/catalog/hcp.59
} 


a: iconic: right hand at right, left hand, "O" shape at left waist<Sylvester entering the
drainpipe>PATH
b: iconic: right hand at right chest moves up to right side of face, left hand, "O" shape
at waist lowers to lap as right hand rises<Sylvester going up inside
drainpipe>PATH
c: iconic: right hand at right side of face moves in toward body and moves up to
forehead changing hand orientation to palm toward down, fingers toward left
<Sylvester going through the drainpipe>PATH
d: iconic: right hand at nose level and moves up to top of head then retracts to nose
level<pipe>GROUND iconic (reduced repetition of previous gesture) right hand at upper chest moves
in toward body to chin level and down away from body to upper chest, small
circular movement, and holds<pipe>GROUND

Rosa has five gestures in Example 7. This shows how segmented her thinking is in English in 1997. They indicate that rather than thinking of the utterance as a whole, she is thinking of each constituent of the sentence individually. Also, besides having a path gesture with the satellite and article through the (7c), she also has a path gesture with the subject the cat (7a) and the verb went.

\begin{tabular}{|l|}
\hline (8) \\
Rosa-Speech and gesture $2006 \quad$ (Stam 2017: 357) \\
[he goes inside / the pipe $\underline{\text { the }}^{*} /$ ] \\
iconic: left hand C-shape at chest level <drainpipe>; right fingers extended thumb \\
tucked in moves in toward left hand, up and around in a circular movement \\
<entering > and then straight up to palm toward center, fingers toward up and retracts \\
to just below right shoulder < left hand = pipe right hand = Sylvester, Sylvester \\
entering and going up the drainpipe>PATH+GROUND
\end{tabular}




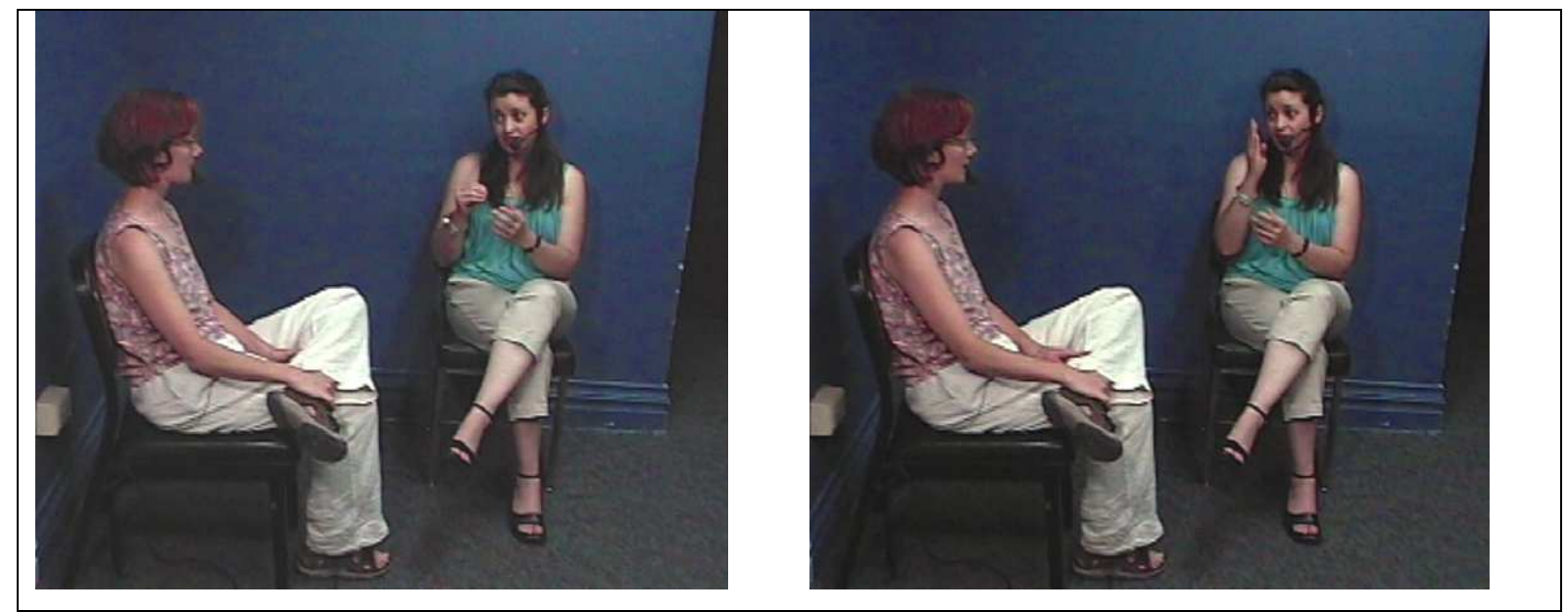

In 2006 (Example 8), Rosa's gestures indicate that her thinking for speaking has changed in English. She is thinking of the utterance as a whole and produces one path and ground gesture with continual movement that co-occurs with the utterance as a whole showing Sylvester going both inside and up the drainpipe.

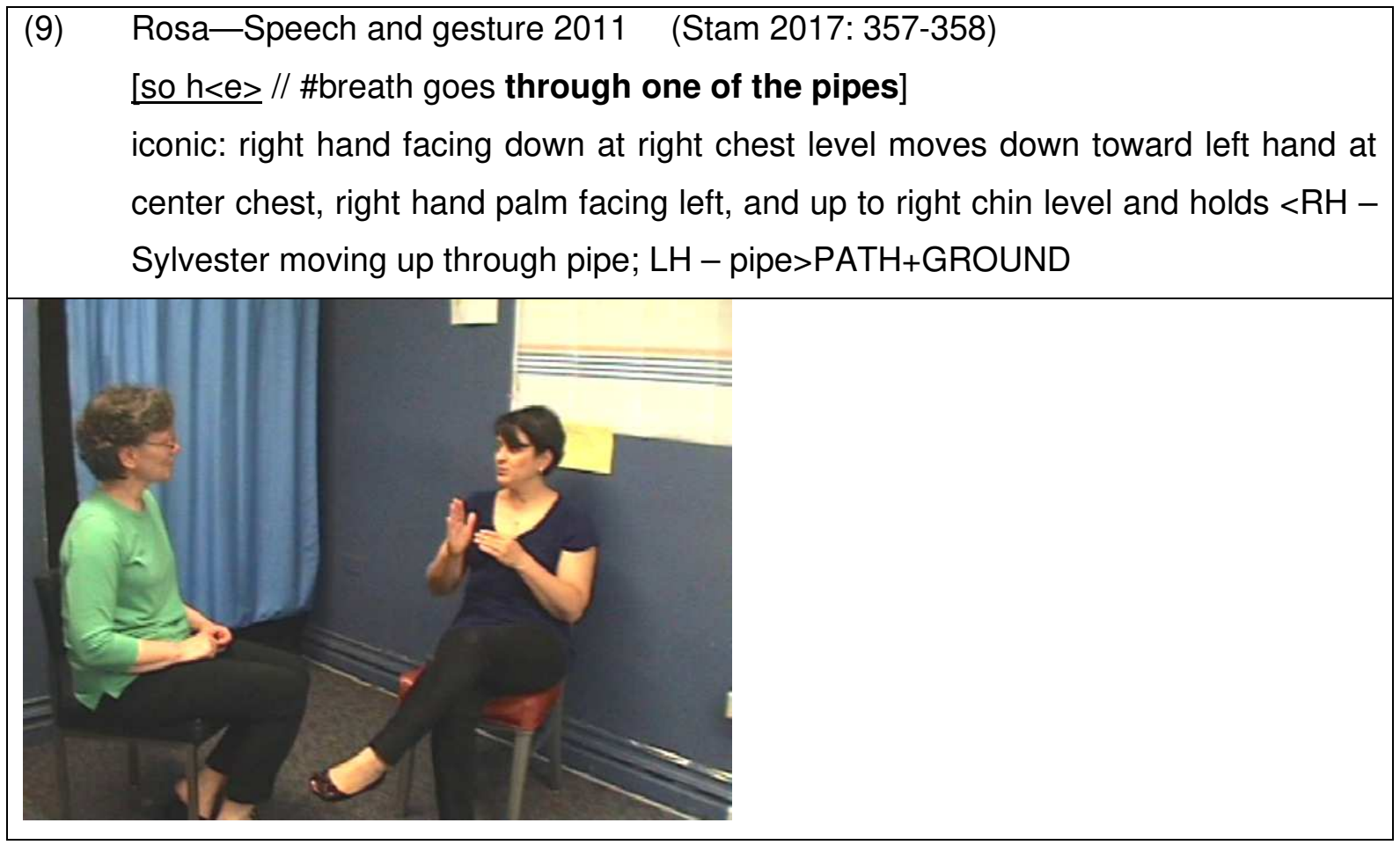

The synchronization of Rosa's gestures in 2011 (Example 9) shows that her thinking for speaking in English has continued to become more English-like. In 2011, She has one path and ground gesture that co-occurs with the satellite and ground elements of the sentence. This is similar to the Native English speaker in Example (10), who produces two path and ground gestures with the satellite elements up and through.

(10) Native English Speaker (Stam 2008: 248) a<a $>$ nd / / he goe[[ss / up / th| rough the pipe]] this time \# 
a: iconic: right hand at low right waist moves from right to left to next to left thigh $<$ Sylvester goes into lower part of the pipe> PATH+GROUND

$\mathrm{b}$ : iconic: right hand "O" shape pops open to loose curved hand and moves up vertically from next to left thigh to left lower chest level<Sylvester goes up inside pipe> PATH+GROUND

Thus, by looking at the speech and gesture examples above, it becomes clear that gesture more clearly indicates how learners are thinking in their L2 than speech alone does.

\subsubsection{Task Effects On Learners' Gestures}

Most of the research on how learners' gestures reveal their conceptualizations has been done with narrative tasks that use a cartoon stimulus. However, it is possible to examine learners' gestures in other tasks as well to see how task affects learners' use of gesture. So far only two studies (Tabensky 2008; Stam 2016) have looked at task effects on learners' gestures.

Tabensky (2008) investigated variation in learners' gestures during two tasks in the L2 classroom an expository task (a short presentation) and a question and answer period following the presentation. She found that the gestures the learners produced were dependent on task: "the learners produced more presentational gestures, gestures that present information (e.g., metaphoric and interactive gestures), during the expository task and more representational gestures, gestures that present content (iconic, lexical, and topic gestures) answering questions" (Stam 2016: 290).

Stam (2016) examined the speech and gesture of a L2 learner in two tasks (an oral proficiency interview and a narrative task) over a fourteen-year period of time (1997 to 2011). She found that the speech and gesture of the learner was greatly affected by the task. In the narrative task, the learner produced primarily iconic gestures and had more gestures per clause even though more clauses were produced in the oral proficiency task. In the oral proficiency task that more approximated a conversation on everyday topics such as work, school, and family, both the learner and the interviewer produced primarily metaphoric gestures. She also found that the interview task could be used to view the learner's conceptualizations and thinking for speaking as well as changes in the interaction between the learner and the interviewer.

For instance, in Example 11, the learner is talking about looking for a job and how she submitted her resume online. She produces two iconic path gestures with the utterance: one on the word through a satellite element and one on the word online a ground element. This indicates that she is thinking for speaking about path according to the English pattern. Her speech alone would not have allowed us to see this. 


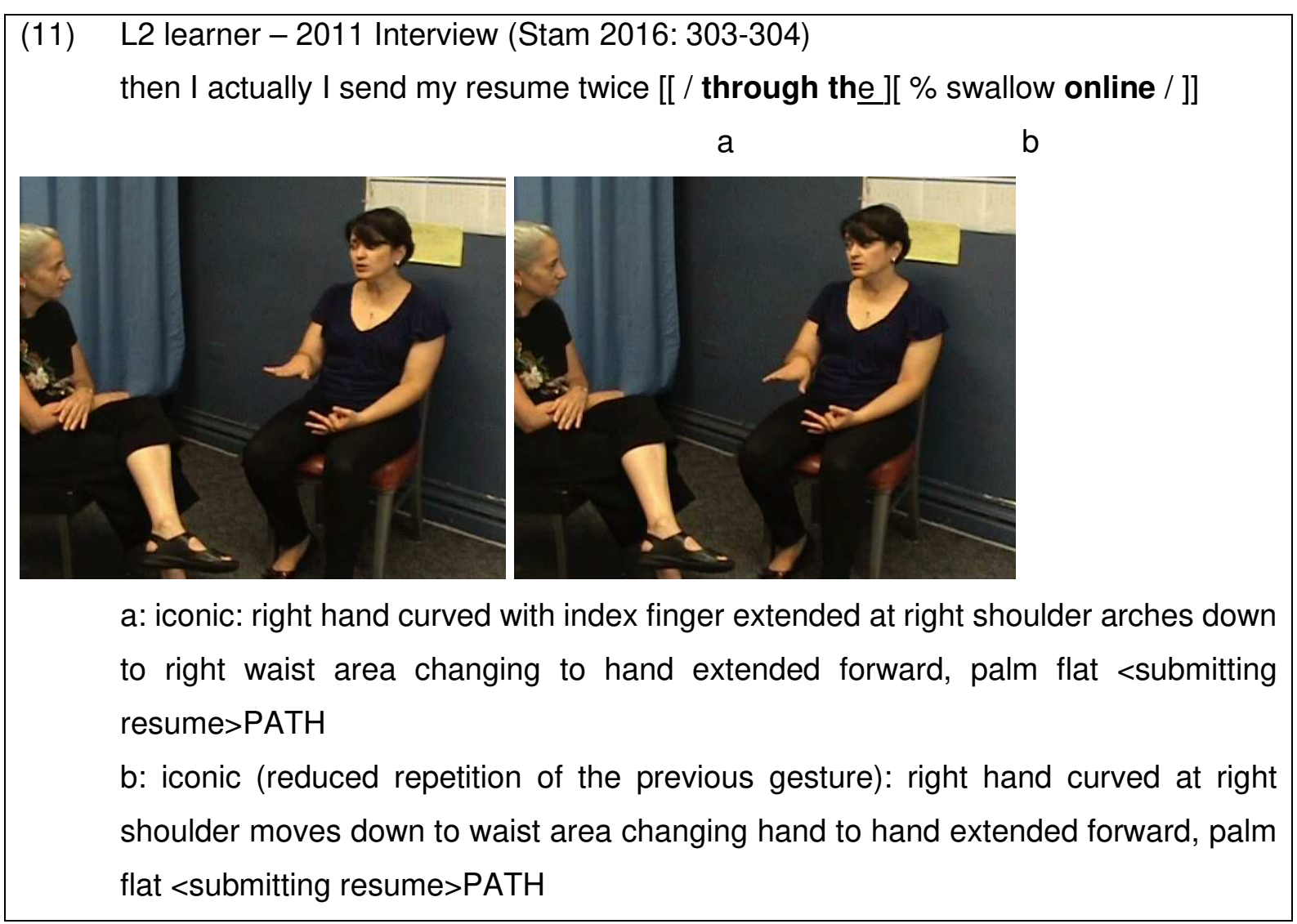

In regard to the development of the interview interaction, Stam found that the last interview had become an actual conversation between peers with overlapping speech and gesture and use of each other's gestures. This would have all been missed by looking at only the participant's speech.

\subsubsection{How Gestures Enhance Foreign Language Learning}

As we have discussed, the gestures produced by learners shed light on their process of language learning, but gestures, especially gestures that are produced by teachers (pedagogical gestures) and taken into account by learners, can also scaffold and reinforce language learning.

Several studies have highlighted the positive effect of gestures and other kinesic (related to the body) cues on L2 listening comprehension (S. Kellerman, 1992; Sueyoshi \& Hardison, 2005) including studies on young children (Tellier, 2008a, 2009). The question of how L2 learners perceive, use, and interpret teachers' gestures in the classroom has been addressed by several researchers, for example, Azaoui (2016), Hauge (1998, 1999), Sime (2001, 2006, 2008), and Tellier (2008a, 2009). They have shown that, even if gestures produced by a language teacher generally help learners' understanding, in some cases certain gestures can lead to misunderstanding because they are ambiguous, too symbolic, or culturally embedded. 


\subsubsection{Gestures and Second Language Memorization}

A number of researchers have explored the question of whether gesture has an effect on L2 memorization. For example, Allen (1995) and Tellier (2008b) have explored the effect of gestures on L2 long-term memorization. Both found a significant effect of gestures on memorization of lexical items, and these results have been supported by more recent studies (de Nooijer et al., 2013; Krönke et al., 2013; Macedonia, 2013; Macedonia \& Klimesch, 2014; Macedonia \& Knösche, 2011; Macedonia et al., 2011; Rowe et al., 2013). On this topic, most research has taken place in artificial conditions (e.g., in a laboratory) except Nakatsukasa's (2016) study, which took place in a classroom context and evaluated the effect of a teacher's corrective reformulations on improving the learning of spatial prepositions (e.g., "in," "on," "under") in an English-as-a-second-language classroom.

The questions now to be addressed are how the ability to use gesture to scaffold language learning operates in the classroom and in what respects this ability can be developed by teachers as a professional skill.

\subsection{Gestures Used By The Language Teachers And Their Functions}

Since Grant and Grant Hennings' pioneering work in 1971 (The teacher moves), teachers' bodies have been regarded as an important feature in the action of teaching. Among the studies on pedagogical gestures based on classroom observations or corpuses are the works of Kellerman (1992), Allen (2000), Pavelin (2002), Lazaraton (2004), Tellier (2008a, 2016), Azaoui (2013, 2014), Denizci and Azaoui (2015). With the evolution of audio-visual tools and technologies, and the recent development of multimodal annotation tools such as Elan (Sloetjes and Wittenburg 2008) research has become more precise and can be used on larger naturalistic corpuses. In addition to the various positive aspects of gestures for language learning that we have already discussed, teachers' gestures in the classroom (and especially in the language class) adopt specific forms and perform particular functions. Some of teachers' pedagogical gestures are routinized and consciously used. They help the learners to focus their attention on the keywords of sentences and thus enable an onomasiological approach (i.e. global) of the language. In previous work, Tellier (2008a) found 3 main pedagogical functions of gestures in the classroom. These are based on the 3 functions elaborated by Dabène (1984) for teacher talk: (a) informing, (b) managing and (c) assessing.

\subsubsection{Gestures to inform about language}

Among information gestures, we find gestures of grammatical information that are used to transmit data related to morphosyntax and temporality (Matsumoto and Dobs 2017), gestures of lexical information to illustrate a word or an idea of the oral speech of the teacher 
and phonological and phonetic information gestures created to help learners master pronunciation and prosody (Smotrova 2017 for example). The information function of the gesture especially during lexical explanation has been extensively studied in actual classrooms (e.g., Seaver 1992; Allen 2000; Lazaraton 2004; Tellier 2016) as well as in online teaching via videoconferencing (Holt, Tellier and Guichon 2015).

Lexical explanation happens when a misunderstanding occurs in class and a teacher can explain the meaning of an item at the request of a learner or because the feedback (or absence of feedback) of the students indicates a misunderstanding. However, the gesture does not occur only when the learner has not understood and the teacher has to set up a repair sequence (Varonis and Gass 1985). On the contrary, we notice in teachers' multimodal discourse, an anticipation of the potential difficulties of comprehension. In short, a teacher anticipates the learner's knowledge, gaps and needs. A gesture is produced by teachers to illustrate a word or idea from their oral speech. They may choose to illustrate one word over another for two main reasons (the two reasons can be combined): (1) because they consider this term particularly important for understanding the overall meaning of the sentence (this is the pivot) and (2) because they assume and anticipate that this word is unknown to the learner and will cause him/her a problem (Tellier, 2008a). Example 12 illustrates this.

(12) In this French class, the student in black says that she does not like to speak in front of
people.
Teacher: juste une personne (picture 1) ou tout le monde (picture 2)? [just one person in
particular or everybody ?]
Student : tout le monde (picture 3) [everybody]

Here the teacher wants some precision and asks whether the learner does not like to speak in front of one person in particular or in front of everybody. He produces two gestures, first an emblem to show number 1 and then an iconic gesture with a flat hand, palm downwards and moving sideways to represent a large amount. In his question, the two keywords are connected to this contrast: one versus everybody. This is why he illustrates the two words with gestures synchronised with his keywords. They are the pivots of the sentence, and he wants to make sure they are understood. Interestingly, the learner reproduces the second gesture when she answers, showing that she has paid attention to and assimilated the teacher's gesture. 


\subsubsection{Gestures to Assess}

The function of assessing (or evaluation) includes gestures to congratulate, approve and report an error. Congratulatory / approving gestures appear more at the end of the learner's intervention, allowing the teacher to seal the end of the answer with a positive assessment. When the statement has errors, the teacher can either interrupt the learner or wait for the end of the statement to intervene. In Example 13, the teacher simply gives feedback on the learner's answer by repeating the correct form of the sentence and showing with a gesture that nothing else should be added.

(13) The students discuss what they enjoyed in the French class during the end of school
term. They have to make sentences with "I enjoyed" (j'ai aimé) and "I less enjoyed" (j'ai
moins aimé). A student says "j'ai moins aimé beaucoup" [I less enjoyed a lot] which is
grammaticaly incorrect. The teacher corrects by repeating "j'ai moins aimé" followed by a
gesture which means "enough" to mean that the sentence is correct with nothing more.

In general, if the teacher reports an error during the learner's production, he or she will tend to do so only non-verbally so as not to interrupt the learner's production. The teacher instead uses the gesture to indicate a problem in the student's response and not to give the correct answer. The learner, knowing where the wrong part is, has just to correct it and can reflect on his mistakes. This evaluation function, especially in the language class, has been the subject of mainly descriptive research (Schachter 1981; Mackey et al. 2007; Faraco 2008).

In the context of the classroom where several speakers contribute to the interaction, the teacher can use gestures to conduct the speech turns. A typical situation occurs when the teacher asks a question and several answers are produced at the same time by the students. In Example 14, the learner in black has just provided an answer that was expected by the teacher (after asking a question to the whole class). He suddenly turns to her, looks at her with a smile and points in her direction. Once again the different kinesic cues coordinate to perform the function of assessing the learner's intervention. 


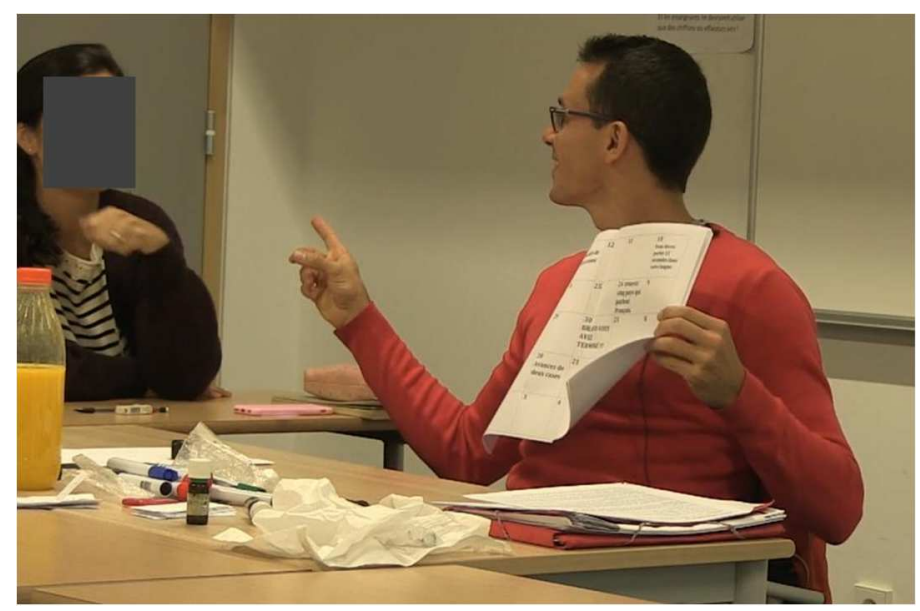

Example 14: Multimodal assessment of a student's answer

\subsubsection{Gestures To Manage The Class}

The third major functional category of pedagogical gestures is the function of management that encompasses both class management gestures (change of activity, start and end of activity, placement of learners / material, punish / scold / silencing, giving instructions) and the management of interactions and participation (regulate flow / volume, repeat, support, interrogate, give voice). This is a function that has gotten little attention in the analysis of teacher's gestures, and when it is mentioned, it is rarely the subject of careful analysis (Grant \& Grant Hennings 1971; Beattie 1977; Barnett 1983) with the exception of Azaoui's work $(2013,2014,2016)$. Is this due to the fact that the function of teacher as animator, making learning more animated, may seem less fundamental to some than informing or evaluating? The question remains. Typically when giving instructions, the keywords can be accompanied by illustrative gestures like in Example 15, when an emblem illustrates "three".

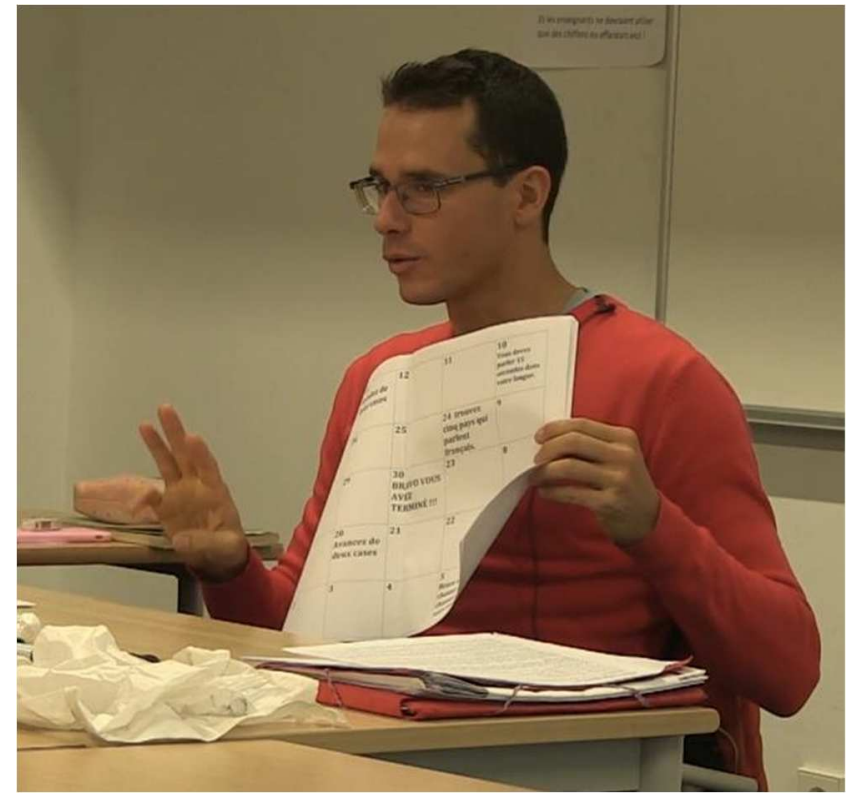

Example 15: par groupes de trois [in groups of three] 
(16) The teacher gives instructions for an activity. The students have to write questions that will be used in the board game they are creating.

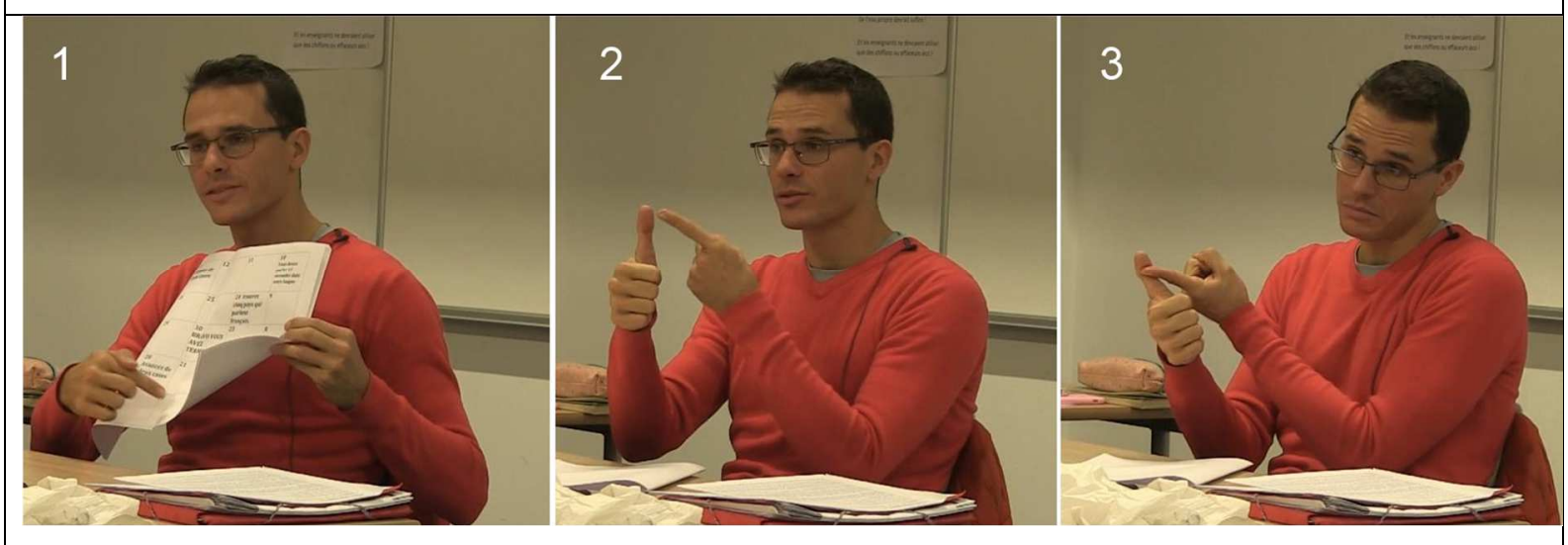

Teacher: trouvez des questions pour chaque case (picture 1) vous pouvez faire des questions de grammaire (picture 2) si vous voulez (picture 3 )

[find questions for each box (picture 1) you can do grammar questions (picture 2) if you want (picture 3)]

In Example 16, a very interesting composition of kinesic movements accompanies the verbal instruction given by the teacher. He first points to the sheet of paper that the learners have received to show where they will have to write their answers; then, he puts down the sheet to release his hands for the rest of the explanation. He starts to enumerate the kind of questions the students can create for their board game (only the first example is given here). Enumerating emblems are used to show different possibilities (the first here), and the emblem is pointed to in order to re-enforce the enumeration. The example of "grammar questions" is nuanced by the head movement and the facial expression of the teacher which implies that doing grammar questions is a possibilty although it might not be the most exciting one. This interesting combination of kinesic cues added to verbal instruction is very typical of a teacher's multimodal discourse (see also Azaoui 2014, 2016).

Finally, as we can see in the picture of Example 16, the teacher's gaze sweeps the entire class to make sure everybody's attention is focused on him. It is a means to catch the learners' attention and include them as partners in the classroom conversation. It is also common to see teachers directing their gestures in order to make them visible to all. This phenomenon of orientation of the gesture towards the interlocutor has already been highlighted by Özyürek (2000) in dyads or triads, in a semicontrol context, and it is interesting to notice the same thing, in an ecological situation, in a class where the teacher is co-enunciator of several learners at the time to use the expression of Azaoui (2014).This capacity to gaze at the whole class to catch everybody's attention is not always acquired by young teachers (Mclntyre et al. 2016; Tellier and Yerian 2018). As we will now discuss, the capacity to use and adapt kinesic 
cues to serve pedagogical functions is not completely innate and develops through training and experience.

\subsection{Gestures Of Future Teachers: A Developmental Approach}

\subsubsection{Pedagogical Features Of Co-Speech Gestures}

Using gestures as a pedagogical tool is not innate and develops over time and experience but also through training. Teachers can adapt their gestures to the language proficiency and the needs of their students to enhance learning as we have seen above. Strikingly, many language teachers are aware of the fact that they use gestures as a scaffold strategy in class: they can actually describe some of the gestures they use as a routine or postures that they tend to adopt for certain pedagogical functions (Tellier \& Cadet, 2018). One can wonder how much of this adaptation is spontaneous and how much is developed through training and experience. Studies on foreigner talk (Ferguson 1975, 1981) have shown that speakers adapt their speech to their foreign interlocutor (slow speech rate, simplification of lexical use, articulation, etc.) but we know little about the gestural adaptation that may occur. One study on gestures in foreigner talk (Adams, 1998) has shown that little gestural adaptation is done when "regular" speakers address non-native speakers though speakers only statistically produce more deictics when addressing non-native speakers. Is this also true for future teachers (i.e. speakers that are sensible to the difficulties that learners may encounter in oral comprehension for instance)? In the Gestures in Teacher Talk (GTT) project we launched in 2009, future teachers of French (enrolled in a training program in Aix en Provence, France) participated in a lexical explanation task with native and non-native speakers of French. They had to explain 12 words to both partners to make them guess these words. Data enabled us to compare how future teachers use gesture and speech and adapt them to the proficiency level of their addressee.

To a certain extent, most future teachers use gestures as a "tool" to enrich their speech when talking to learners of French (Tellier, Stam \& Ghio, 2021). For example, the degree of iconicity in their gestures is higher (more iconics and deictics are produced than metaphorics and emblems for instance) as well as the size of the gestures (larger gestures are produced with learners of French). Similar patterns are found when giving explanations in an L1 depending on the age of the addressee. For instance, Campisi \& Özyürek (2013) found that adult speakers produced gestures that were more informative and bigger for children than for adults.

In Example 17 from the GTT corpus, the future teacher (on the left) explains the word grimper (to climb) first to a native partner, then a non-native one. In both conditions she says 
almost the same sentence and produces an iconic gesture (pretending to climb the rocks) but with the non-native partner, the gesture is larger and goes above her head.

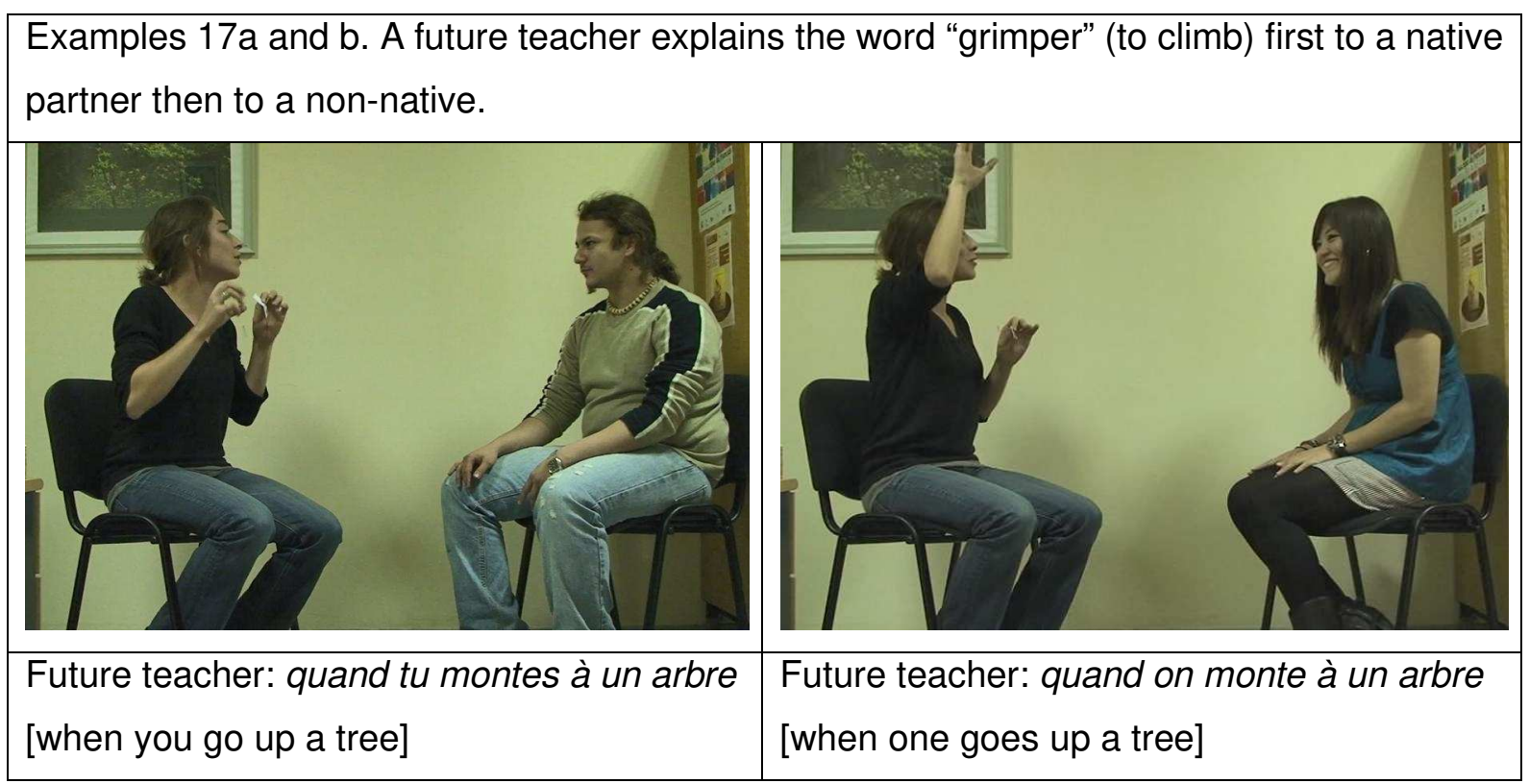

Example 17: To climb (from GTT corpus)

Similarly, future teachers seem to adapt their gestures during their conversational exchange when their non-native partner does not understand them. In Example 18, we can see a future teacher (on the left) explaining the phrase to "grate cheese" to a non-native partner. He first produces an iconic gesture showing the size and the shape of a little piece of cheese. He explains the action of grating and says that the goal is to have little pieces of cheese in the end. The gesture is rather static and shows one referent (the small piece of cheese), which is a keyword (i.e. a word whose comprehension is necessary to get the meaning of the sentence). His non-native interlocutor does not understand so he explains again and focuses his gestures on the specific description of the action (the verbal explanation remains roughly the same: "little pieces [of cheese]"). This time, he shows the action of grating cheese and all the little pieces falling down from the grate. His gestures show the grate, the original piece of cheese, all the little grated pieces and the action of falling from the grate. This sophisticated ensemble of gestures does not only illustrate a single keyword (like the other explanation) but the whole action. This happens because the first explanation with one gesture did not work. We can see that in case of misunderstanding, future teachers tend to add more meaning in their gestures and make them more complex. 

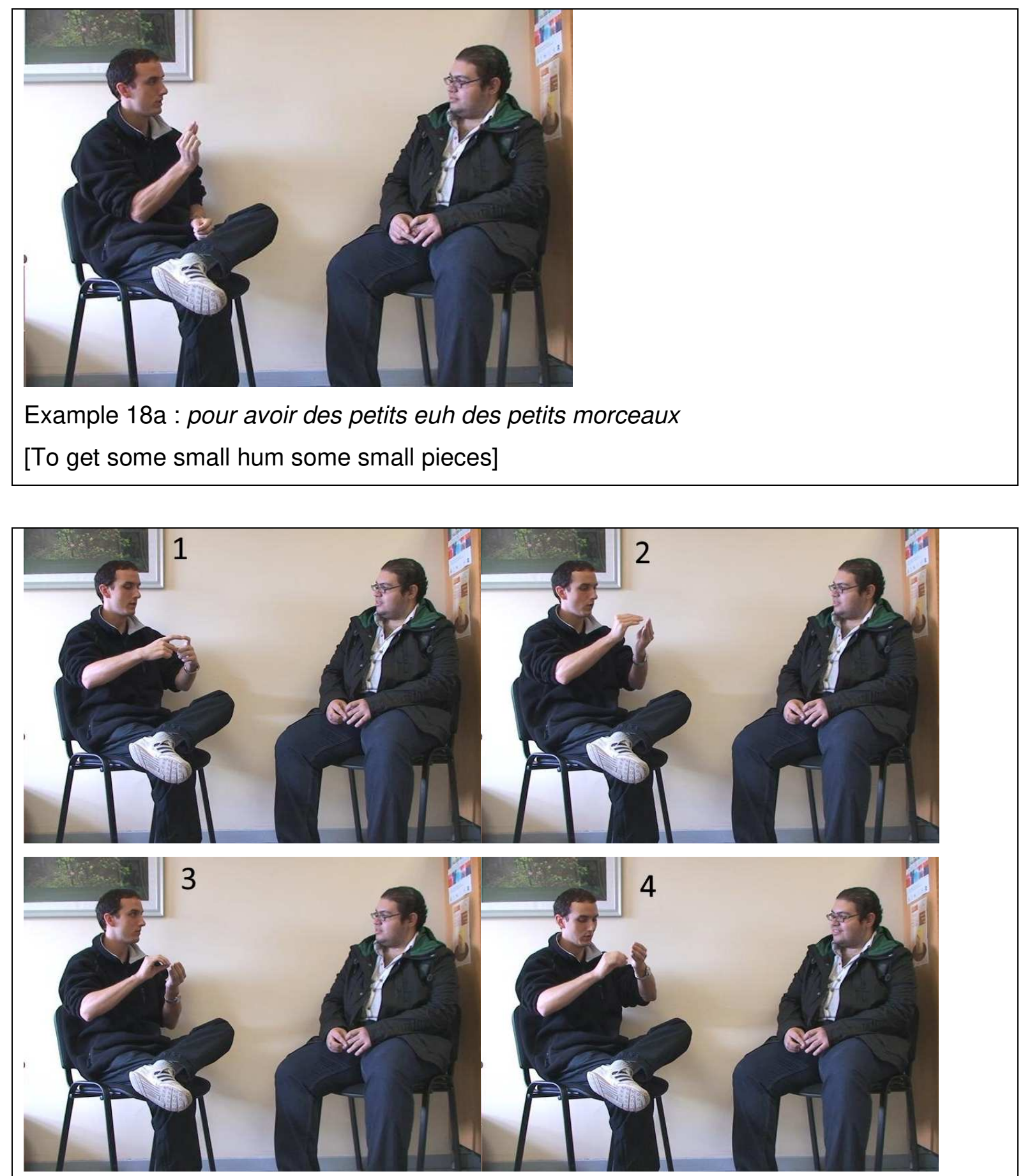

Example 18b: si j'ai un un morceau (picture 1) de fromage ouais (390ms) ${ }^{6}$ et je le frotte (picture 2) $(1340 \mathrm{~ms})$ ouais $(1630 \mathrm{~ms})$ et il y a des petits (picture 3$)$ morceaux de fromage (picture 4)

[if I have a a piece (picture 1) of cheese yeah and I rub it (picture 2) yeah and there are little (picture 3) pieces of cheese (picture 4)]

\footnotetext{
${ }^{6}$ The numbers with (ms) correspond to speech pauses, in milliseconds
} 
A final feature specific to gestures produced in a pedagogical context, is the use of gestures during speech pauses. In fact, future teachers (as experienced teachers) use gestures during speech pauses to facilitate comprehension. They tend to produce speech pauses after and/or before keywords to isolate them and facilitate the segmentation of the spoken chain, and they sometimes produce gestures during these pauses to help the learners understand the meaning of these keywords (see Stam and Tellier 2017; Tellier, Stam and Bigi 2013). Interestingly they do not use this technique with native interlocutors in the GTT corpus.

\subsubsection{Pedagogical Gestures In Teacher Training}

Pedagogical gestures and the use of the body in class receive little attention in language teacher training (Tellier and Cadet 2014; Tellier and Yerian 2018). Based on the analysis of classroom films and training sessions, Tellier and Yerian (2018) have identified the major difficulties that future language teachers encounter with the use of their body in class: the relevant use of gaze, the posture and location of the body in class, and the use of the body (mainly hands) to demonstrate meaning. This is why several researchers have advocated that effective use of the body as a pedagogical tool is an acquired skill and that teacher education programs should incorporate workshops or training modules on this topic. These modules could include (1) theoretical elements about gestures in communication, in teaching and how they can be culturally-specific, (2) practice opportunities focused on exploiting embodied multimodality (integrating use of the body, voice, and other material support) and (3) sessions of self-observation in stimulated recall sessions (Tellier and Cadet 2014; Tellier and Yerian 2018).

\subsection{Conclusion}

Considering the importance of gestures in L2 learning and teaching that has been discussed in this chapter, we are convinced that studies in Second Language Acquisition (SLA) and Second Language Teaching (SLT) should include more analysis of gestures to better understand how speech and gestures are linked in production and perception of a foreign language. As far as SLA is concerned, gestures tell us a lot about how L2 learners are thinking, and consequently, they can be used as a means to assess both L2 development and L2 thinking. This can be done in both experimental tasks and in more naturalistic settings. Both kinds of data are necessary if we are to truly understand L2 acquisition. Additionally, we need more studies that look at learners' gestures in multiple tasks as this will give us a fuller picture of how they use the L2. We also need more longitudinal studies in multiple languages. Finally, more training is necessary for researchers who are interested in investigating $L 2$ and gesture. This can be done as workshops at conferences or workshops sponsored by universities. Similarly, for SLT, the analysis of the kinesic activity (not only hand gestures but also gaze, 
facial expressions, postures) of teachers and learners would enable research in language education to get a better understanding of what is going on in the classroom (in terms of interaction, activities and learning). Future research should not only focus on assessing the effect of teacher training on the use of pedagogical gestures by young teachers but also look at professional development over the teacher's lifetime and how experience can affect gesture production in class. Studies combining experimental methods and naturalistic data would lead to a better view on how pedagogical gestures are used in class and their effect on learning. Given what we know about gestures and what they can tell us about L2 learning and teaching, they can no longer be ignored in SLA and SLT research.

\section{References}

Adams, Thomas W. 1998. Gesture in foreigner talk. University of Pennsylvania dissertation.

Agar, Michael. 1994. Language shock: Understanding the culture of conversation. New York: William Morrow \& Co.

Aguiló Mora, Francisca \& Eduardo Negueruela-Azarola. 2015. Motion for the other through motion for the self: The complexities of giving-directions for advanced heritage learners of Spanish. In Kioka Masuda, Carlee Arnett \& Ángela Labarca (eds.), Cognitive linguistics and sociocultural theory. Applications for second and foreign language teaching, 73-100. Berlin: Mouton De Gruyter.

Allen, Linda Quinn. 1995. The effects of emblematic gestures on the development and access of mental representations of French expressions. The Modern Language Journal 79(4). 521-529.

Allen, Linda Quinn. 2000. Nonverbal Accommodations in Foreign Language Teacher Talk. Applied Language Learning 11(1). 155-176.

Azaoui, Brahim. 2013. One Teacher, Two Instructional Contexts. Same Teaching Gestures?.

TiGeR: Tilburg Gesture research meeting, 1-4. Tilburg, Netherlands. Jun 2013. <hal$\underline{00833026>}$

Azaoui, Brahim. 2014. Multimodalité des signes et enjeux énonciatifs en classe de FL1/FLS. In Marion Tellier and Lucile Cadet (eds.), Le corps et la voix de l'enseignant: mise en contexte théorique et pratique, 115-126. Paris: Éditions Maison des Langues.

Azaoui, Brahim. 2016. Mise en abyme des interactions didactiques. Recherches en didactique des langues et des cultures 13(1). http://rdlc.revues.org/1472 (accessed 17 septembre 2018)

Barnett, Marva. A. 1983. Replacing Teacher Talk with Gestures : Nonverbal communication in the Foreign Language Classroom. Foreign Language Annals 16(3). 439-448. 
Beattie, Geoffrey \& Jane Coughlan. 1998. Do iconic gestures have a functional role in lexical access? An experimental study on the effects of repeating a verbal message on gesture production. Semiotica 119(3/4). 221-249.

Beattie, Geoffrey \& Jane Coughlan. 1999. An experimental investigation of the role of iconic gestures in lexical access using the tip-of-the-tongue phenomenon. British Journal of Psychology 90. 35-56.

Beattie, Nicholas. 1977. Non-Verbal aspects of the teaching and learning of foreign languages. Audio-Visual Language Journal 15. 175-181.

Brown, Amanda \& Marianne Gullberg. 2008. Bidirectional crosslinguistic influence in L1-L2 encoding of manner in speech and gesture: A study of Japanese speakers of English. Studies in Second Language Acquisition 30. 225-251.

Brown, Amanda. 2008. Gesture viewpoint in Japanese and English: Cross-linguistic interactions between two languages in one speaker. Gesture 8. 256-276.

Brown, Amanda. 2015. Universal development and L1-L2 convergence in bilingual construal of manner in speech and gesture in Mandarin, Japanese, and English. In Emmanuel Bylund \& Panos Athanasopolous (guest eds.), The language and thought of motion in second language speakers. Modern Language Journal 99(S1). 66-82.

Campisi, Emanuela \& Asli Özyürek, A. 2013. Iconicity as a communicative strategy : Recipient design in multimodal demonstrations for adults and children. Journal of Pragmatics 47(1). 14-27.

Choi, Soojung \& James P. Lantolf. 2008. Representation and embodiment of meaning in L2 communication: Motion events in the speech and gesture of advanced L2 Korean and L2 English speakers. Studies in Second Language Acquisition 30. 191-224.

De Nooijer, Jacqueline, Van Gog Tamara, Paas Fred \& Rolf Zwaan. 2013. Effects of imitating gestures during encoding or during retrieval of novel verbs on children's test performance. Acta Psychologica 144(1). 173-179.

Denizci, Can \& Brahim Azaoui. 2015. Reconsidering Gesture Space for Naturalistic Teaching Gesture Research. Istanbul Journal of Innovation in Education 1(3). 97-109.

Drijvers, Linda \& Asli Özyürek. 2016. Visual context enhanced: The joint contribution of iconic gestures and visible speech to degraded speech comprehension. Journal of Speech, Language, and Hearing Research. 1-11. DOI: 10.1044/2016_JSLHR-H-16-0101.

Faraco, Martine. 2008. Gestes et prosodie didactiques dans l'enseignement des structures langagières en FLE. Actes du colloque Enseigner les structures langagières en FLE, Bruxelles, 20-22 mars 2008. http://gramm-fle.ulb.ac.be/95/enseigner-les-structureslangagieres-en-fle-bruxelles-20-22-mars-2008-actes/(accessed 17 September 2018)

Ferguson, Charles. 1975. Toward a characterization of English foreigner talk. Anthropological 
Linguistics 17. 1-14.

Ferguson, Charles. 1981. 'Foreigner talk' as the name of a simplified register. International Journal of the Sociology of Language 28. 9-18.

Grant, Barabra M. \& Dorothy Grant Hennings. 1971. The Teacher moves. An analysis of nonverbal activity. New York: Teacher College Press, Columbia University.

Gullberg, Marianne \&, Steven G. McCafferty. 2008. Introduction to gesture and SLA: Toward an integrated approach. Studies in Second Language Acquisition 30. 133-146.

Gullberg, Marianne, Kees de Bot, \& Virginia Volterra. 2008. Gestures and some key issues in the study of language development. Gesture 8(2). 149-179.

Gullberg, Marianne. 1998. Gesture as a Communication Strategy in Second Language Discourse. A Study of Learners of French and Swedish. Lund: Lund University Press.

Gullberg, Marianne. 2010. Methodological reflections on gesture analysis in second language acquisition and bilingualism research. Second Language Research 25(4). 1-28.

Hauge, Elizabeth. 1998. Gesture in the EFL class: an aid to communication or a source of confusion? In Danielle Killick \& Mike Parry (eds.), Cross-cultural capability - the why, the ways and the means: New theories and methodologies in language education, 271-280. Proceedings of the conference at Leeds Metropolitan University Dec. 1997.

Hauge, Elizabeth. 1999. Some common emblems used by British English teachers in EFL classes. In Danielle Killick \& Mike Parry (eds.), Cross-cultural capability - promoting the discipline: Marking boundaries and crossing borders, 405-420. Proceedings of the conference at Leeds Metropolitan University Dec. 1998.

Holt, Ben, Tellier Marion \& Nicolas Guichon. 2015. The use of teaching gestures in an online multimodal environment: the case of incomprehension sequences. In Ferre, G. \& M. Tutton (eds.), Gesture and Speech in Interaction - 4th edition. Nantes, 2-4 September 2015, pp. 149-154. https://hal.archives-ouvertes.fr/hal-01195646/document (accessed 17 September 2018)

Jenkins, Susan \& Isabel Parra. (2003). Multiple layers of meaning in an oral proficiency test: The complementary roles of nonverbal, paralinguistic, and verbal behaviors in assessment decisions. The Modern Language Journal 87(1). 90-107.

Kellerman, Eric \& Anne-Marie van Hoof. 2003. Manual accents. International Review of Applied Linguistics 41. 251-269.

Kellerman, Susan. 1992. 'I See What You Mean' : The Role of Kinesic Behaviour in Listening and Implications for Foreign and Second Language Learning. Applied Linguistics 13(3). 239-258.

Kendon, Adam. 2004. Gesture: Visible action as utterance. Cambridge/New York: Cambridge University Press. 
Krönke, K.-Martin, Müller Karsten, Friederici, Angela D. \& Hellmuth Obrig. (2013). Learning by doing? The effect of gestures on implicit retrieval of newly acquired words. Cortex, 49(9). 2553-2568.

Lazaraton, Anne. 2004. Gestures and speech in the vocabulary explanations of one ESL teacher : A microanalytic inquiry. Language Learning 54(1). 79-117.

Macedonia Manuela \& Thomas R Knösche. 2011. Body in Mind: How Gestures Empower Foreign Language Learning. Mind, Brain, and Education 5(4). 196-211.

Macedonia, Manuela \& Wolfgang Klimesch. 2014. Long-term effects of gestures on memory for foreign language words trained in the classroom. Mind, Brain, and Education 8. 74-88.

Macedonia, Manuela, Müller Karsten \& Angela D. Friederici. 2011. The impact of iconic gestures on foreign language word learning and its neural substrate. Human Brain Mapping 32. 982-998.

Macedonia, Manuela. 2013. Learning a second language naturally: the voice movement icon approach. Journal of Educational and Developmental Psychology 3. 102-116.

Mackey, Alison, Al-Khalil Maymona, Atanassova Gergana, Hama Mika, Logan-Terry Aubrey \& Kimi Nakatsukasa. 2007. Teachers' intentions and learners' perceptions about corrective feedback in the L2 classroom. Innovations in Language Learning and Teaching, 1(1). 129152

Matsumoto, Yumi \& Abby Mueller Dobs. 2017. Pedagogical gestures as interactional resources for teaching and learning tense and aspect in the ESL grammar classroom. Language Learning 67. 7-42.

McIntyre, Nora, Mainhard Tim \& Robert Klassen. 2016. Are you looking to teach? Cultural, Temporal and Dynamic Insights into Expert Teacher Gaze. » Learning and Instruction 49. 41-53.

McNeill, David. 1992. Hand and mind. Chicago: The University of Chicago Press

McNeill, David. 2005. Gesture and thought. Chicago: The University of Chicago Press.

McNeill, David. 2012. How language began: Gesture and speech in human evolution. Cambridge/New York: Cambridge University Press.

Nakatsukasa, Kimi. 2016 Efficacy of gestures and recasts on the acquisition of locative prepositions. Studies in Second Language Acquisition 38(4). 771-799

Nambiar, Mohana K. \& Cecilia Goon. 1993. Assessment of oral skills: A comparison of scores obtained through audio recordings to those obtained through face-to-face evaluation. RELC Journal: A Journal of Language Teaching and Research in Southeast Asia 24(1). 15-31.

Negueruela, Eduardo, James P. Lantolf, Stefanie Rehn Jordan, \& Jaime Gelabert. 2004. The "private function" of gesture in second language speaking activity: A study of motion verbs and gesturing in English and Spanish. International Journal of Applied Linguistics 14. 113147. 
Neu, Joyce. 1990. Assessing the role of nonverbal communication in the acquisition of communicative competence in L2. In Robin C. Scarcella, Elaine S. Andersen \& Stephen D. Krashen (eds.), Developing communicative competence in a second language, 121-138. New York: Newbury House Publishers.

Özyürek, Asli. 2000. The influence of addressee location on spatial language and representational gestures of direction. In David McNeill (ed.) Language and gesture, 64-83. Cambridge University Press.

Pavelin, Bogdanka. 2002. Le geste à la parole. Toulouse : Presses Universitaires du Mirail.

Rowe, Meredith L., Silverman Rebecca D. \& Bridget E. Mullan. 2013. The role of pictures and gestures as nonverbal aids in preschoolers' word learning in a novel language. Contemporary Educational Psychology 38(2). 109-117.

Schachter, Jacquelyn. (1981). The hand signal system. TESOL Quarterly 15(2). 125-138.

Seaver, Paul W. 1992. Pantomime as an L2 Classroom Strategy. Foreign Language Annals, 25(1). 21-31.

Sime, Daniela. 2001. The use and perception of illustrators in the foreign language classroom. Christian Cavé, Isabelle Guaïtella, \& Serge Santi (eds.), Oralité et gestualité. Interactions et comportements multimodaux dans la communication, 582-585. Paris: L'Harmattan.

Sime, Daniela. 2006. What do learners make of teachers' gestures in the language classroom ?. In Marianne Gullberg (ed.) Special issue on Gestures and SLA, International Review of Applied Linguistics 44(2). 211-230.

Sime, Daniela. 2008. "Because of her gesture, it's very easy to understand" - Learners' perceptions of teachers' gestures in the foreign language class. In Steven G. McCafferty, \& Gale Stam (eds.), Gesture: Second language acquisition and classroom research, 259279. New York NY: Routledge.

Slobin, Dan I. 1991. Learning to think for speaking: Native language, cognition, and rhetorical style. Pragmatics 1. 7-26.

Slobin, Dan I. 2006. What makes manner of motion salient? Explorations in linguistic typology, discourse, and cognition. In Maya Hickmann \& Stéphane Robert (eds.), Space in languages: Linguistic systems and cognitive categories, 59-81. Amsterdam: John Benjamins.

Sloetjes, Han \& Peter Wittenburg. 2008. Annotation by category - ELAN and ISO DCR. In Proceedings of the 6th International Conference on Language Resources and Evaluation (LREC 2008). 816-820, Marrakech, Maroc.

Smotrova, Tetyana. 2017. Making Pronunciation Visible: Gesture In Teaching Pronunciation. TESOL Quarterly 51.59-89. doi:10.1002/tesq.276 
Stam, Gale. 2001. Lexical failure and gesture in second language development. In Christian Cavé, Isabelle Guaïtella, \& Serge Santi (eds.), Oralité et gestualité: interactions et comportements multimodaux dans la communication, 271-275. Paris, France: L'Harmattan.

Stam, Gale. 2006a. Changes in patterns of thinking with second language acquisition. University of Chicago dissertation,

Stam, Gale. 2006b. Thinking for speaking about motion: L1 and L2 speech and gesture. International Review of Applied Linguistics 44. 143-169.

Stam, Gale. 2008. What gestures reveal about second language acquisition. In Steven G. McCafferty \& Gale Stam (eds.), Gesture: Second language acquisition and classroom research, 231-255. New York: Routledge.

Stam, Gale. 2010. Can a L2 speaker's patterns of thinking for speaking change? In ZhaoHong Han \& Teresa Cadierno (eds.), Linguistic relativity in SLA: Thinking for speaking, 59-83. Clevedon: Multilingual Matters.

Stam, Gale. 2012. Gestes et recherche de mots en langue seconde. In Robert Vion, Alain Giacomi \& Claude Vargas (eds), La corporalité du langage: Multimodalité, discours et écriture, Hommage à Claire Maury-Rouan, 55-71. Aix en Provence: Publications de I'Université de Provence.

Stam, Gale. 2013. Second language acquisition and gesture. In Carol A. Chapelle (ed.), The encyclopedia of applied linguistics. Oxford: Blackwell Publishing Ltd. doi: 10.1002/9781405198431.wbeal1049.

Stam, Gale. 2014. Further changes in L2 thinking for speaking? In Cornelia Müller, Alan Cienki, Ellen Fricke, Silva H. Ladewig, David McNeill \& Jana Bressem (eds.), Body- LanguageCommunication: An international handbook on multimodality in human interaction. Volume 2, 1875-1886. Handbooks of Linguistics and Communication Science/Handbücher zur Sprach- und Kommunikationswissenschaft. Berlin/New York: Mouton De Gruyter.

Stam, Gale. 2015. Changes in thinking for speaking: A longitudinal case study. In Emmanuel Bylund \& Panos Athanasopolous, (guest eds.), The language and thought of motion in second language speakers. Modern Language Journal 99(S1). 83-99.

Stam, Gale. 2016. Gesture as a window onto conceptualization in multiple tasks: Implications for second language teaching. Yearbook of the German Cognitive Linguistics Association (GCLA) 4. 289-314.

Stam, Gale. 2017. Verb framed, satellite framed or in between? A L2 learner's thinking for speaking in her L1 and L2 over 14 years. In Iraide Ibarretxe-Antuñano (ed.), Motion and space across languages: theory and applications, 329-365. Philadelphia/ Amsterdam: John Benjamins.

Stam, Gale. 2018a. Gesture and speaking a second language. In Rosa Alonso (ed.), Speaking in a L2, 51-69. Philadelphia/Amsterdam: John Benjamins. 
Stam, Gale. 2018b. Gesture as a window onto conceptualization in second language acquisition: A Vygotskian perspective. In James P. Lantolf, Matthew E. Poehner \& Merrill Swain (eds.), Routledge handbook of sociocultural theory and second language development, 165-177. London/New York: Routledge.

Stam, Gale \& Kimberly Buescher. 2018. Gesture research. In Aek Phakiti, Peter De Costa, Luke Plonsky \& Sue Starfield (eds.), Palgrave handbook of applied linguistics research methodology, 793-809. London: Palgrave Macmillan.

Stam, Gale \& Steven G. McCafferty, 2008. Gesture studies and second language acquisition: A review. In Steven G. McCafferty \& Gale Stam (eds.), Gesture: Second language acquisition and classroom research, 3-24. New York: Routledge.

Stam, Gale, \& Marion Tellier. 2017. The sound of silence: The functions of gestures in pauses in native and non-native interaction. In Ruth Breckinridge Church, Martha W. Alibali \& Spencer D. Kelly (eds.), Why gesture? How the hands function in speaking, thinking and communicating, 353-377. Philadelphia/Amsterdam: John Benjamins.

Sueyoshi, Ayano \& Debra M., Hardison. 2005. The role of gestures and facial cues in second language listening comprehension. Language Learning 55(4). 661-699.

Tabensky, Alexis. 2008. Expository discourse in a second language classroom: How learners use gesture. In Steven G. McCafferty \& Gale Stam (eds.), Gesture: Second language acquisition and classroom research, 298-320. New York \& London: Routledge.

Talmy, Leonard. 2000. Towards a cognitive semantics. Vol. II: Typology and process in concept structuring. Cambridge, MA: MIT Press.

Tellier, Marion. 2008a. Dire avec des gestes. In Chnane-Davin, F. \& Cuq, J.P. (eds.), Du discours de l'enseignant aux pratiques de l'apprenant en classe de français langue étrangère, seconde et maternelle. Le Français dans le monde, recherche et application 44. 40-50.

Tellier, Marion. 2008b. The effect of gestures on second language memorisation by young children. In Marianne Gullberg \& Kees de Bot (eds.), Special issue Gestures in language development. Gesture 8(2). 219-235.

Tellier, Marion. 2009. Usage pédagogique et perception de la multimodalité pour l'accès au sens en langue étrangère, in Bergeron, R., Plessis-Belaire, G., Lafontaine, L. (eds.), La place des savoirs oraux dans le contexte scolaire d'aujourd'hui, 223-245, Québec : Presses de I'Université du Québec, 223-245. ISBN-13: 978-2760523708

Tellier, Marion. 2014. Donner du corps à son cours. In Marion Tellier \& Lucile Cadet (eds.), Le corps et la voix de l'enseignant: théorie et pratique,101-114. Paris: Éditions Maison des Langues. ISBN-13: 978-8484439301 
Tellier, Marion. 2016. Prendre son cours à bras le corps. De l'articulation des modalités kinésiques avec la parole. Recherches en didactique des langues et des cultures 13(1). http://rdlc.revues.org/474 (accessed 17 september 2018)

Tellier, Marion \& Lucile Cadet. 2013. Dans la peau d'un natif : Etat des lieux sur l'enseignement des gestes culturels. In Fabrice Barthelemy (ed.), L'enseignement des langues étrangères face aux évolutions des systèmes éducatif et médiatique, La Revue Française d'Education Comparée 9. 111-140.

Tellier, Marion \& Lucile Cadet (eds.). 2014. Le corps et la voix de l'enseignant: théorie et pratique. Paris: Éditions Maison des Langues.

Tellier, Marion \& Lucile Cadet. 2018. Si le corps vous en dit. Prendre conscience de son corps pédagogique en formation. Expertise au service des acteurs du français dans le monde. Mélanges pour les 50 ans du BELC, 57-65. Sèvres : CIEP Éditions.

Tellier, Marion \& Gale Stam. 2012. Stratégies verbales et gestuelles dans l'explication lexicale d'un verbe d'action. In Véronique Rivière (ed.), Spécificités et diversité des interactions didactiques, 357-374. Paris, Riveneuve éditions.

Tellier, Marion, Stam Gale \& Brigitte Bigi. 2013. Gesturing while pausing in conversation: Selforiented or Partner-oriented?. Proceedings of TIGER- Tilburg Gesture Research Meeting Conference. http://tiger.uvt.nl/list-of-accepted-papers.html (Accessed 18_September 2018)

Tellier, Marion, Stam Gale \& Alain Ghio. 2021. Handling Language: How future language teachers adapt their gestures to their interlocutor. Gesture 20(1). 30-62.

Tellier, Marion \& Keli Yerian. 2018. Mettre du corps à l'ouvrage : Travailler sur la mise en scène du corps du jeune enseignant en formation universitaire. Les Cahiers de l'APLIUT.

Varonis, Evangeline Marlos \& Susan Gass. 1985. Non-native/non-native Conversations: A Model For Negotiation of Meaning. Applied Linguistics 6. 71-90.

von Raffler-Engel, Walburga. 1980. Kinesics and paralinguistics: A neglected factor in second language research. Canadian Modern Language Review 36(2). 225-237.

Wylie, Laurence. 1985. Language learning and communication. The French Review 58(6). 777-785. 